Veterinary Research 12 (2): 19-26, 2019

ISSN: $1993-5412$

(C) Medwell Journals, 2019

\title{
Prevailing Bacterial Zoonoses in Sub-Saharan Nigeria: A 10 Years Retrospective Study in Veterinary Hospitals
}

\author{
${ }^{1}$ Yakubu Yusuf, ${ }^{2}$ Usman Bashir and ${ }^{1}$ Sani Sulaiman \\ ${ }^{1}$ Department of Public Health and Preventive Medicine, Faculty of Veterinary Medicine, \\ Usmanu Danfodiyo University Sokoto, Sokoto, Nigeria \\ ${ }^{2}$ Ministry of Animal Health and Fisheries Development, Sokoto, Nigeria
}

\begin{abstract}
Zoonoses are diseases transmissible from vertebrate animals to humans. They occur worldwide and present a significant threat to both human and animal health. A retrospective study was conducted to determine the bacterial zoonoses prevalent in the sub-Saharan Region of Nigeria. Two veterinary hospitals in Sokoto State were identified and data on diagnosed cases of microbial diseases between January 2006 and December 2015 were collected. A total of 14,832 cases were recorded of which $3,351(22.6 \%)$ were considered to be of zoonotic importance while the remaining 11,481 (77.4\%) were strictly animal diseases. All the microbial zoonoses recorded were bacterial infections comprising bovine brucellosis $(21.10 \%)$, ovine brucellosis $(37.45 \%)$, listeriosis $(39.27 \%)$, leptospirosis $(1.55 \%)$ and glanders $(0.63 \%)$. Brucellosis and leptospirosis were observed to prevail throughout the year without any seasonal variation. While leptospirosis and glanders were seen to occur mostly in the rainy season. Ovine species had the highest proportion of zoonotic diseases recorded (27.53\%) while equine species had the lowest $(5.59 \%)$. The findings provided more information on the most commonly encountered bacterial zoonoses in animals in the sub-Saharan part of Nigeria. There is the need for public enlightenment on the potential health threats and the appropriate preventive measures against these diseases. Concerned authorities in the study area need to establish an all-encompassing monitoring programme for zoonotic diseases in both humans and animals.
\end{abstract}

Key words: Bacterial zoonoses, sub-Saharan Nigeria, veterinary hospitals, leptospirosis, zoonotic diseases

\section{INTRODUCTION}

Zoonotic diseases are infectious diseases that are naturally transmitted from vertebrate animals to humans and vice versa (Wang and Crameri, 2014). The term "Zoonosen" was believed to be coined by Rudolf Virchow in 1885 as a synonym for "infections by contagious animal poisons". Later in 1894, Galli-Valerio published a manual titled "Zoonoses: diseases communicable from animal to man". These diseases have been recognized many centuries ago and are caused by all types of pathogenic microbes including bacteria, viruses, fungi, parasites and prions (Wang and Crameri, 2014). The organisms are responsible for a substantial number of diseases in man which have been associated with significant morbidity and mortality. It has been estimated that $61 \%$ of known human pathogens are zoonotic (Taylor et al., 2001) and make up $80 \%$ of the CDC list of bio-threat agents of concern (Anonymous, 2017). In the world over, the food safety concern and economic impact of zoonotic diseases cannot be overemphasized. The endemicity of some zoonotic diseases greatly affect the African economy due to trade barriers on animals and animal products imposed on some states (Anonymous, 2018). Needless to say that the cost of controlling the diseases as well as production losses experienced by farmers also have a significant impact on the livestock industry. Over $70 \%$ of livestock resources in Nigeria are located in the Northern Region where majority of the populace are rural subsistent farmers and livestock producers. Most of the livestock in the region are indigenous animals produced within the country. Although, a sizeable number of animals are imported from neighbouring countries via. legal and illegal routes along the land borders. Unhealthy animals smuggled into the country could ultimately be taken to slaughter houses or introduced into new herds for breeding purpose. Hence, there is growing concern over the potential transmission and spread of important zoonotic diseases such as brucellosis and latent bovine tuberculosis amongst herds in the region. The low level of public awareness, neglect and misdiagnosis of zoonotic diseases contribute to the

Corresponding Author: Yakubu Yusuf, Department of Public Health and Preventive Medicine, Faculty of Veterinary Medicine, Usmanu Danfodiyo University Sokoto, Sokoto, Nigeria 
under-reporting of these diseases in the region. Despite reports on some zoonotic infections endemic in Nigeria (Coker et al., 2000; Akinpelu et al., 2011), little is known about the prevailing zoonoses diagnosed in veterinary hospitals in the sub-Saharan Region of the country. Thus, this study was conducted to investigate the occurrence of microbial zoonoses diagnosed in animals presented to two veterinary hospitals in Sokoto State, Nigeria.

\section{MATERIALS AND METHODS}

Study area: The study was conducted in Sokoto Metropolis, the capital of Sokoto State, Nigeria. Two veterinary hospitals within the study area namely: Usmanu Danfodiyo University Sokoto Veterinary Teaching Hospital (UDUS-VTH) and the Sokoto State Veterinary Hospital (SSVH) were enrolled in the study. Sokoto State is located at latitude $130 \mathrm{~N}$ and between longitudes $408^{\prime}$ and $6054^{\prime} \mathrm{E}$ in the extreme North Western part of Nigeria, covering an area of approximately $56,000 \mathrm{~km}^{2}$ (Blench, 1999). The state shares border with Niger Republic to the North, Kebbi State to the South and Zamfara State to the East. Based on the 2006 National population census, the state has a projected population of about 4,244,399 (Anonymous, 2006). The state is ranked second in the livestock population in Nigeria with an average of 3 million cattle, 4 million goats, 3.85 million sheep, 0.8 million camels and a million poultry (Anonymous, 2008).

Data collection: Following approval by the management of the two veterinary hospitals, relevant information on cases presented and diagnoses made were collected. Case files and diagnostic records from 2006-2015 were carefully, examined to obtain vital information such as date of presentation, animal species (bovine, ovine, canine, equine), sex, age and diagnosis. The diagnostic processes in both hospitals involve taking history of the patient, clinical manifestation, laboratory investigation and postmortem examination. A total of 14,832 cases were recorded within the 10 years study period comprising 4,744 cattle, 9,339 sheep, 373 dogs and 376 horses.

Data analysis: The data obtained were entered into Microsoft Excel 2013 for descriptive statistics. The distribution pattern of the diseases diagnosed during the 10 years period was determined. Proportions of the zoonotic diseases were calculated based on species, year and disease type. The results obtained were presented in narratives and figures.

\section{RESULTS AND DISCUSSION}

A total of 14,832 cases of bacterial diseases comprising 10,084 cases in SSVH and 4,748 cases in VTH-UDUS were diagnosed between January 2006 and December 2015 (Table 1). Most of the cases (77.4\%) were strictly animal diseases while $22.6 \%$ were potential zoonoses diagnosed in different animal species. Sokoto State Veterinary Hospital (SSVH) had the highest number of cases recorded (10084) with 19.63\% (1979) being zoonotic infections while Usmanu Danfodiyo University Sokoto Veterinary Teaching Hospital (UDU-VTH) had a total of 4,748 cases with $28.9 \%$ (1372) diagnosed to be zoonotic (Fig. 1). Within the period under study, 2009 had the highest proportion of zoonotic diseases recorded (28.27\%), followed by $2015(25.52 \%), 2013(23.45 \%), 2010$ $(23.30 \%), 2014(22.71 \%), 2012(22.05 \%), 2007(21.84 \%)$, $2006(20.15 \%), 2008$ (20.06\%) and 2011 (19.47\%) (Fig. 2). Based on animal species presented within the study period, the proportions of zoonotic diseases diagnosed in ovine, bovine, canine and equine species were 27.53 , $14.90,13.94$ and $5.59 \%$, respectively (Fig. 3). Among the

Table 1: Number of bacterial diseases diagnosed between 2006 and 2015 in

\begin{tabular}{lccr}
\multicolumn{4}{c}{ SSVH and UDUS-VTH } \\
Zoonotic Diseases & Non-Zoonotic & \\
Variables & (ZD) & Diseases (NZD) & Total \\
\hline SSVH & 1979 & 8105 & 10084 \\
UDUS-VTH & 1372 & 3376 & 4748 \\
Total & 3351 & 11481 & 14832 \\
\hline
\end{tabular}

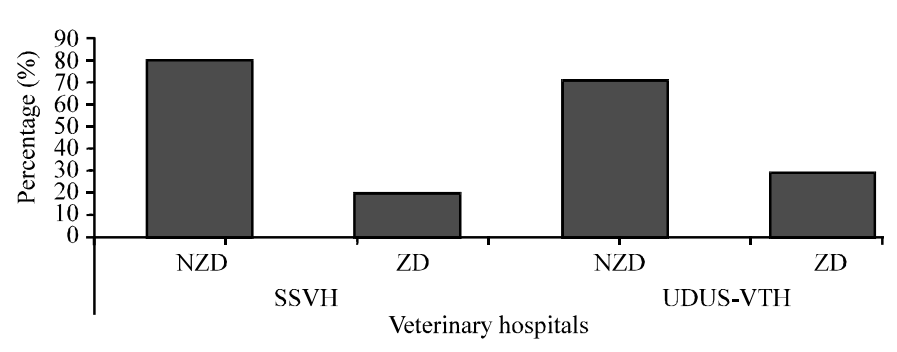

Fig. 1: Percentage distribution of zoonotic and non-zoonotic diseases diagnosed between 2006 and 2015 


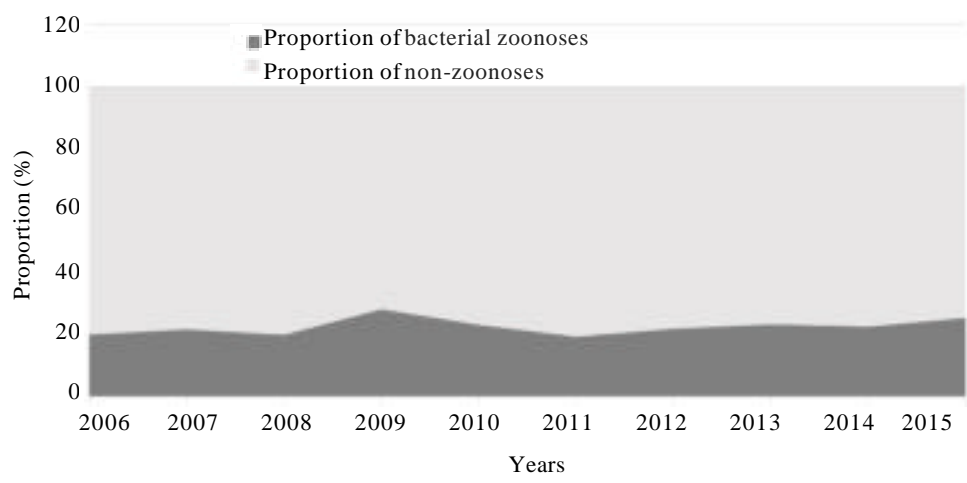

Fig. 2: Annual proportion of bacteria zoonoses and non-zoonotic diseases diagnosed between 2006 and 2015

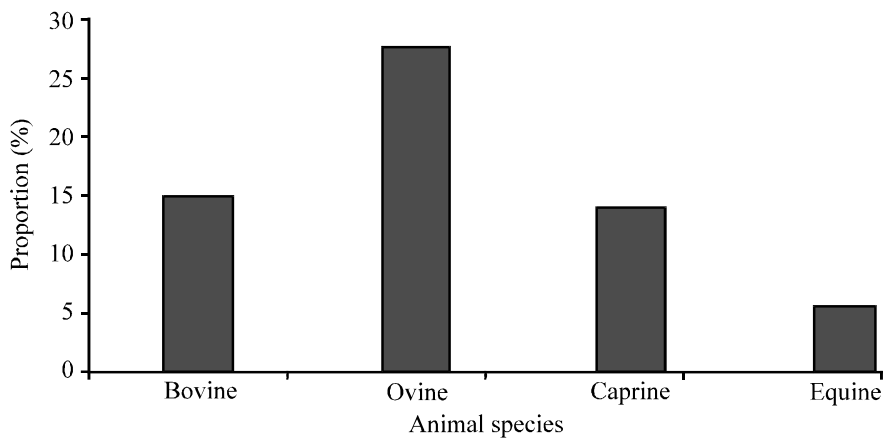

Fig. 3: Proportion of animal species diagnosed with bacterial zoonoses between 2006 and 2015

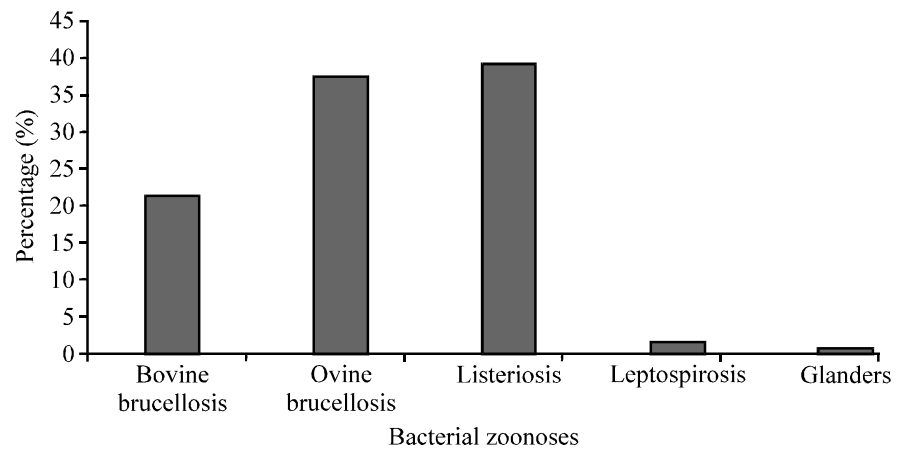

Fig. 4: Percentage distribution of bacterial zoonoses diagnosed between 2006 and 2015

zoonotic diseases encountered, listeriosis had the highest proportion of $39.27 \%$, followed by ovine brucellosis $(37.45 \%)$, bovine brucellosis $(21.10 \%)$, leptospirosis $(1.55 \%)$ and glanders $(0.63 \%)$ (Fig. 4). Based on annual prevalence, brucellosis and leptospirosis were observed to prevail throughout the year without salient seasonal variation while leptospirosis and glanders were mostly recorded during the rainy season (Fig. 5).

Brucellosis is one of the neglected endemic zoonoses reported in Nigeria over 40 years ago (Alausa and
Awoseyi, 1976). Cross-sectional studies in different animal species across the country revealed presence of the disease, especially, in the Northern Region which has the highest population of livestock resources (Cadmus et al., 2006; Adamu et al., 2007; Junaidu et al., 2006; Cadmus et al., 2011; Junaidu et al., 2008; Adamu et al., 2014; Jajere et al., 2016). Risk of human brucellosis has been associated with consumption of unpasteurized milk and close contact with infected animals, especially, among occupationally exposed 


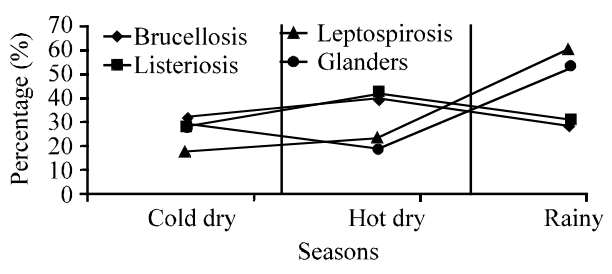

Fig. 5: Seasonal proportion of bacterial zoonoses diagnosed between 2006 and 2015

individuals such as veterinarians, abattoir workers/animal handlers and livestock farmers (Alausa and Awoseyi 1976; Baba et al., 2001; Kozukeev et al., 2006; Ofukwu et al., 2007; Aworh et al., 2013a; Pandit and Pandit, 2013). During the period under study, there was no salient seasonal variation in the occurrence of the disease in animals. However, studies in Egypt and Greece have reported a significant increase in the disease prevalence in animals during Spring (Avdikou et al., 2005; Haggag et al., 2016). Cases of bovine and ovine brucellosis in this study were believed to be caused by Brucella melitensis and Brucella abortus, respectively. The infections were diagnosed based on clinical presentations and Rose Bengal Plate agglutination Test (RBPT) as earlier described (Strys zak, 1986; Blasco et al., 1994; Ferreira et al., 2003). These Brucella species are highly infectious and have been incriminated in most human brucellosis (Acha and Szyfres, 2003; Corbel, 2006). Despite the tradition of consuming fresh unpasteurized milk in Sub-Saharan Nigeria (Yakubu et al., 2018) and reports on endemicity of human brucellosis in most developing African countries, there are no confirmed reports of human brucellosis diagnosed in hospitals in Nigeria. However, serological studies in some selected populations revealed occurrence of the infection in the country (Alausa, 1977; Aworh et al., 2013b; Ducrotoy et al., 2014; Adesokan et al., 2016). Thus, the human perspective of the disease is believed to be under-reported due to neglect, misdiagnosis and lack of adequate laboratory facilities as earlier identified (Godfroid et al., 2005; Folagbade et al., 201 7; Franc et al., 2018).

Listeria monocytogenes is a zoonotic bacterial pathogen responsible for listeriosis in ruminants (circling disease in sheep) and foodborne infection in humans (DiMaio, 2000). It is an environmental pathogen that frequently contaminates ready-to-eat food items such as vegetables and fruits (Allerberger and Wagner, 2010; Linke et al., 2014). Following infection, animals could shed the organism in milk which if consumed unpasteurized can result to life-threatening conditions, especially, in the young and old. Veterinary hospitals in the study area diagnose the disease based on cardinal signs such as still birth, abortion and circling gait in sheep (Vazquez-Boland et al., 2001; Dhama et al., 2015). Individuals, in close contact with animals such as livestock farmers, animal attendants and veterinarians are at high risk of infection, if hand hygiene is not regularly observed. The use of manure by irrigation farmers is a very common practice in Nigeria due to scarcity of fertilizer. This traditional farming method could expose the public to pathogens such as Listeria species when contaminated manure is used to produce vegetables. Although, there are no documented cases of human listeriosis in the study area, reports of the disease in pregnant women and neonates manifesting with meningitis and meningoencephalitis in other parts of the country have been described (Nwaiwu, 2015).

Leptospirosis is the most widespread zoonosis in the world reported in all continents except Antarctica (Adler and Moctezuma, 2010). It is caused by over 250 serovars of Leptospira species found in a wide range of animal species (Levett, 2001; Cerqueira and Picardeau, 2009). Human leptospirosis is a neglected endemic disease in Africa, especially, amongst people in close contact with animals and (Allan et al., 2015). The disease is also transmissible via. consumption of water contaminated with urine of infected dogs. Leptospirosis is mostly under-reported in economically poor countries in Africa due to lack of resources and human capacity (Maudlin et al., 2009). The cases of leptospirosis recorded in this study were all diagnosed in local breeds of dogs using clinical signs and microscopic agglutination test (Ananda et al., 2008). Higher reporting rates were recorded during rainy season when the weather is humid and warm which favours the survivability of the pathogen in the environment as earlier described (Adler and Moctezuma, 2010; Hartskeerl et al., 2011; De Vries et al., 2014). Dog handling has earlier been reported to be associated with leptospirosis in Nigeria following an outbreak in a dog kennel (Awosanya et al., 2013). Thus, individuals in close contact with infected dogs and other susceptible animals such as cattle and pigs are at risk of contracting the disease (Ngbede et al., 2013; Abiayi et al., 2015; Ajayi et al., 2018). The public is also, at risk of infection when infected dogs contaminate water bodies such as ponds and streams that serve as major sources of drinking water in the rural areas (Ishaku et al., 2011). Serological evidence of human leptospirosis have earlier been reported in Nigeria amongst kennel workers, abattoir workers and even healthy individuals (Ezeh et al., 1991; Onyemelukwe, 1993; Agunloye et al., 2001; Awosanya et al., 2013). 
Glanders is mainly a disease of solipeds such as horses, donkeys and mules caused by Burkholderia mallei. The disease has been eradicated in the United States, Western Europe, Australia and North America but still present in Africa, Eastern Europe, Asia, South America and Middle East (Wittig et al., 2006; Slater, 2013; Van Zandt et al., 2013). Burkholderia mallei is a zoonotic bacteria of great public health importance and have been reported in occupationally exposed persons such as veterinarians, horse attendants and laboratory workers (Howe and Miller, 1947; Georgiades and Fishman, 2001; Srinivasan et al., 2001). Glanders is seriously under-reported in Nigeria partly due to neglect by concerned authorities, preference for traditional medication by horse owners and inadequate veterinary hospitals. However, this study revealed presence of the disease in the Sub-Saharan Region of the country. The veterinary hospitals in the study area diagnosed the disease by some of its characteristic presentation such as pneumonia, nodules or purulent crater-like ulcers (farcy pipes) on the legs, especially, along the course of the lymphatic vessels, anaemia, neutrophilic leukocytosis and firm milary granulomatous nodules with caseonecrotic centre seen at postmortem (Al-Ani and Roberson, 2007). The higher number of the disease recorded during rainy season could be attributed to the need for a moist environment for the bacteria to survive and multiply as earlier described (Currie, 2014; Malik et al., 2015). To date, there is no documented case of human glanders in the study area. However, infection with the causative agent (Burkholderia mallei) was once diagnosed in a traveler who visited Nigeria and returned to the United Kingdom (Salam et al., 2011). Thus, characterizing the disease of utmost public health importance, especially, among immunocompromised individuals.

\section{CONCULSION}

This study has provided information on some under-reported prevailing microbial zoonoses in Sub-Saharan Nigeria. It has also, revealed potential animal to human transmission of the diseases in the study area, especially, amongst individuals in close contact with animals. Occupationally exposed individuals such as veterinarians, animal handlers, abattoir workers and livestock farmers need to take precautionary measures when dealing with animals. The public particularly rural communities need to be enlightened on health threat posed by the prevailing zoonotic diseases and be educated on appropriate preventive measures. Concerned authorities in the study area need to establish an all-encompassing monitoring programme for zoonotic diseases in both animals and humans in the study area.

\section{ACKNOWLEDGEMENT}

The researchers wish to acknowledge the cooperation and understanding of the veterinarians, laboratory personnel and administrative staff of the Sokoto State Veterinary Hospital (SSVH) and Usmanu Danfodiyo University Sokoto Veterinary Teaching Hospital (UDU-VTH).

\section{REFERENCES}

Abiayi, E.A., H.I. Inabo, E.D. Jatau, A.A. Makinde and T.T. Sar, 2015. Seroprevalence of Leptospira antibodies in cattle slaughtered for sale in some North central states of Nigeria. Res. J. Vet. Sci., 8: 21 28.

Acha, P.N. and B. Szyfres, 2003. Zoonoses and Communicable Diseases Common to Man and Animals: Parasitoses. 3rd Edn., PAHO, WHO, Scientific Publication, Washington, DC., USA., ISBN13: 9789275115800 , Pages: 395.

Adamu, N.B., A.E.J. Okoh and U.J. Azunku, 2007. Prevalence of brucellosis in nomadic herds of dromedaries in Borno State, Nigeria. J. Camel Pract. Res., 14: 135-138.

Adamu, S.G., A.O. Tijjani, N.N. Atsanda and N.B. Adamu, 2014. Serological survey of brucella antibodies in cattle breeding herds in Northeastern Nigeria. J. Vet. Adv., 4: 599-603.

Adesokan, H.K., P.I. Alabi and M.A. Ogundipe, 2016. Prevalence and predictors of risk factors for Brucellosis transmission by meat handlers and traditional healers' risk practices in Ibadan, Nigeria. J. Prev. Med. Hyg., 57: E164-E171.

Adler, B. and A.D.L.P. Moctezuma, 2010. Leptospira and leptospirosis. Vet. Microbiol., 140: 287-296.

Agunloye, C.A., F.O. Alabi, S.O. Odemuyiwa and O.D. Olaleye, 2001. Leptospirosis in Nigerian: A seroepidemiological survey. Indian Vet. J., 78: 371 375.

Ajayi, O.L., R.E. Antia, O.E. Ojo, M.O. Olaniyi and O.J. Awoyomi et al., 2018. Preliminary studies on pathogenic Leptospira spp. In slaughtered pigs in Abeokuta, Ogun State, Nigeria. Bull. Anim. Health Prod. Afr., 66: 35-43.

Akinpelu, A.O., O.O. Oyewole, A.C. Odole and R.O.Olukoya, 2011. Prevalence of musculoskeletal pain and health seeking behaviour among occupational drivers in Ibadan, Nigeria. Afr. J. Biomed. Res., 14: 89-94. 
Al-Ani, F.K. and J. Roberson, 2007. Glanders in horses: A review of the literature. Vet. Arh., 77: 203-218.

Alausa, K.O., 1977. Brucellosis, epidemiology and practical problems of control in Nigeria. Pub. Health, 91: 141-146.

Alausa, O. and A. Awoseyi, 1976. Brucellosis: The situation in Western Nigeria. Trop. Geog. Med., 28: 54-59.

Allan, K.J., H.M. Biggs, J.E. Halliday, R.R. Kazwala and V.P. Maro et al., 2015. Epidemiology of leptospirosis in Africa: A systematic review of a neglected zoonosis and a paradigm for one health in Africa. PLoS Negl. Trop. Dis., 9: 1-25.

Allerberger, F. and M. Wagner, 2010. Listeriosis: A resurgent foodborne infection. Clin. Microbiol. Infect., 16: 16-23.

Ananda, K.J., T. Suryananarayana, P.R. Prathiush, R. Sharada and P.E. D'souza, 2008. Diagnosis and treatment of Leptospirosis in a dog-a case report. Vet. World, 1: 278-279.

Anonymous, 2006. Preliminary report on final 2006 census result. National Population Commission (NPC), Abuja, Nigeria.

Anonymous, 2008. Beef up your profits by investing in Sokoto State's livestock sector. Space Station Integration \& Promotion Center (SSIPC), Tsukuba, Japan.

Anonymous, 2017. Bioterrorism agents/diseases. Centers for Disease Control and Prevention (CDC), Atlanta, Georgia, USA.

Anonymous, 2018. Health and consumer protection for animal and plant products. European Commission Governing body of protected sites, Brussels, Belgium.

Avdikou, I., V. Maipa and Y. Alamanos, 2005. Epidemiology of human brucellosis in a defined area of Northwestern Greece. Epidemiol. Infect., 133: 905-910.

Aworh, M.K., E. Okolocha, J. Kwaga, F. Fasina and D. Lazarus et al., 2013a. Human brucellosis: Seroprevalence and associated exposure factors among abattoir workers in Abuja, Nigeria-2011. Pan Afr. Med. J., Vol. 16. 10.11604/pamj. 2013.16.103.2143

Aworh, M.K., E. Okolocha, J. Kwaga, F. Fasina and D. Lazarus et al., 2013b. Human brucellosis: Seroprevalence and associated exposure factors among abattoir workers in Abuja, Nigeria-2011. Pan African Med. J., 16: 103-111.

Awosanya, E.J., P. Nguku, A. Oyemakinde and O. Omobowale, 2013. Factors associated with probable cluster of Leptospirosis among kennel workers in Abuja, Nigeria. Pan Afr. Med. J., 16: 16.
Baba, M.M., S.E. Sarkindared and F. Brisibe, 2001. Serological evidence of brucellosis among predisposed patients with pyrexia of unknown origin in the North eastern Nigeria. Central Eur. J. Public Health, 3: 158-161.

Blasco, J.M., B. Garin-Bastuji, C.M. Marin, G. Gerbier and J. Fanlo et al., 1994. Efficacy of different Rose bengal and complement fixation antigens for the diagnosis of Brucella melitensis infection in sheep and goats. Vet. Rec., 134: 415-420.

Blench, R., 1999. Traditional Livestock Breeds: Geographical Distribution and Dynamics in Relation to the Ecology of West Africa. 1st Edn., Overseas Development Institute, Portland House Slag Place, London.

Cadmus, S.I.B., H.K. Adesokan, O.O. Ajala, W.O. Odetokun and L.L. Perrett et al., 2011. Seroprevalence of Brucella abortus and B. canis in household dogs in southwestern Nigeria: A preliminary report. J. South Afr. Vet. Assoc., 82: 56-57.

Cadmus, S.I.B., I.F. Ijagbone, H.E. Oputa, H.K. Adesokan and J.K. Stack, 2006. Serological survey of brucellosis in livestock animals and workers in Ibadan, Nigeria. Afr. J. Biomed. Res., 9: 163-168.

Cerqueira, G.M. and M. Picardeau, 2009. A century of Leptospira strain typing. Infect. Genet. Evol., 9: 760-768.

Coker, A.O., R.D. Isokpehi, B.N. Thomas, A.F. Fagbenro-Beyioku and S.A. Omilabu, 2000. Zoonotic infections in Nigeria: Overview from a medical perspective. Acta Trop., 76: 59-63.

Corbel, M.J., 2006. Brucellosis in Humans and Animals. World Health Organization, Geneva, Switzerland, ISBN-13:9789241547130.

Currie, B.J., 2014. Burkholderia pseudomallei and Burkholderia mallei: Melioidosis and Glanders. In: Mandell, Douglas and Bennett's Principles and Practice of Infectious Diseases, Mandell, G.L., J.E. Bennett, R. Dolin and R.G. Douglas (Eds.). Churchill Livingstone Elsevier, Philadelphia, Pennsylvania, USA., ISBN:9781455748013, pp: 2541-2551.

De Vries, S.G., B.J. Visser, I.M. Nagel, M.G. Goris and R.A. Hartskeerl et al., 2014. Leptospirosis in Sub-Saharan Africa: A systematic review. Intl. J. Infect. Dis., 28: 47-64.

Dhama, K., K. Karthik, R. Tiwari, M.Z. Shabbir and S. Barbuddhe et al., 2015. Listeriosis in animals, its public health significance (food-borne zoonosis) and advances in diagnosis and control: A comprehensive review. Vet. Q., 35: 211-235. 
DiMaio, H., 2000. Listeria infection in women. Prim. Care Update OB. GYNS, 7: 40-45.

Ducrotoy, M.J., W.J. Bertu, R.A. Ocholi, A.M. Gusi and W. Bryssinckx et al., 2014. Brucellosis as an emerging threat in developing economies: Lessons from Nigeria. PLoS Negl. Trop. Dis., 8: 1-18.

Ezeh, A.O., A.A. Adesiyun, P.B. Addo, W.A. Ellis and A.A. Makinde et al., 1991. Serological and cultural examination for human leptospirosis in Plateau State, Nigeria. Cent. Afr. J. Med., 37: 11-15.

Ferreira, A.C., R. Cardoso, I.T. Dias, I. Mariano and A. Belo et al., 2003. Evaluation of a modified Rose Bengal test and an indirect enzyme-linked immunosorbent assay for the diagnosis of Brucella melitensis infection in sheep. Vet. Res., 34: 297-305.

Folagbade, O.B., A.G. Adesiyun, A.T. Olayinka, A. Randawa and U. Bawa, 2017. Seroprevalence of brucellosis among women with miscarriage at Ahmadu Bello University Teaching Hospital, Zaria. Trop. J. Obstetrics. Gynaecology, 34: 145-151.

Franc, K.A., R.C. Krecek, B.N. Hasler and A.M. Arenas-Gamboa, 2018. Brucellosis remains a neglected disease in the developing world: A call for interdisciplinary action. BMC. Publ. Health, 18: 1-9.

Georgiades, C. and E.K. Fishman, 2001. Clinical image. Glanders disease of the liver and spleen: CT evaluation. J. Comp. Assist. Tomography, 25: 91-93.

Godfroid, J., A. Cloeckaert, J.P. Liautard, S. Kohler and D. Fretin et al., 2005. From the discovery of the Malta fever's agent to the discovery of a marine mammal reservoir, brucellosis has continuously been a re-emerging zoonosis. Vet. Res., 36: 313-326.

Haggag, Y.N., H.A. Samaha, M.A. Nossair and H.S. Mohammad, 2016. Monitoring of ruminant sera for the presence of Brucella antibodies in Alexandria province. Alexandria J. Vet. Sci., 51: 290-295.

Hartskeerl R.A., M. Collares-Pereira and W.A. Ellis, 2011. Emergence, control and re-emerging leptospirosis: Dynamics of infection in the changing world. Clin. Microbiol. Infect, 17: 494-501.

Howe, C. and W.R. Miller, 1947. Human glanders: Report of six cases. Am. Int. Med., 26: 93-115.

Ishaku, H.T., M.R. Majid, A.A. Ajayi and A. Haruna, 2011. Water supply dilemma in Nigerian rural communities: Looking towards the sky for an answer. J. Water Res. Prot., 3: 598-606.

Jajere, S.M., N.N. Atsanda, A.A. Bitrus, T.M. Hamisu and A.O. Ayo, 2016. Seroprevalence of brucellosis among cattle slaughtered in three municipal abattoir of Gombe state, Northeastern Nigeria. Vet. World, 9: 1082-1086.
Junaidu, A.U. S.I. Oboegbulem, G.H. Sharubutu and A.I. Daneji, 2006. Brucellosis in camels (Camelus dromedaries) slaughtered in Sokoto, Northwestern Nigeria. Anim. Product. Res. Adv., 2: 158-160.

Junaidu, A.U., S.I. Oboegbulem and M.D. Salihu, 2008. Seroprevalence of brucellosis in prison farm in Sokoto, Nigeria. Asian J. Epidemiol., 1: 24-28.

Kozukeev, T.B., S. Ajeilat, E. Maes and M. Favorov, 2006. Risk factors for brucellosis-Leylek and Kadamjay districts, Batken Oblast, Kyrgyzstan, January-November, 2003. MMWR. Morb. Mortal. Wkly. Rep. Suppl., 55: 31-34.

Levett, P.N., 2001. Leptospirosis. Clin. Microbiol. Rev., 14: 296-326.

Linke, K., I. Ruckerl, K. Brugger, R. Karpiskova and J. Walland et al., 2014. Reservoirs of Listeria species in three environmental ecosystems. Appl. Environ. Microbiol., 80: 5583-5592.

Malik, P., H. Singha, S.K. Goyal, S.K. Khurana and B.N. Tripathi et al., 2015. Incidence of Burkholderia mallei infection among indigenous equines in India. Vet. Rec. Open, 2: 1-7.

Maudlin, I., M.C. Eisler and S.C. Welburn, 2009. Neglected and endemic zoonoses. Philos. Trans. R. Soc. B. Biol. Sci., 364: 2777-2787.

Ngbede, E.O., M.A. Raji, C.N. Kwanashie and E.C. Okolocha, 2013. Serosurvey of Leptospira spp. serovar Hardjo in cattle from Zaria, Nigeria. Rev. Med. Vet., 164: 85-89.

Nwaiwu, O., 2015. An overview of Listeria species in Nigeria. Intl. Food Res. J., 22: 455-465.

Ofukwu, A.R., C.A. Yohanna and H.A. Abuh, 2007. Brucella infection among hospital patients in Makurdi, North Central Nigeria. J. Med. Pharm. Sci., 3: $63-71$.

Onyemelukwe, N.F., 1993. A serological survey for Leptospirosis in the Enugu area of Eastern Nigeria among people at occupational risk. J. Trop. Med. Hyg., 96: 301-304.

Pandit, D.P. and P.T. Pandit, 2013. Human brucellosis: Are we neglecting an enemy at the backyard?. Med. J. Dr. DY Patil Univ., 6: 350-358.

Salam, A.P., N. Khan, H. Malnick, D.T.D. Kenna and D.A.B. Dance et al., 2011. Melioidosis acquired by traveler to Nigeria. Emerging Infect. Dis., 17: 1296-1298.

Slater, J., 2013. From glanders to Hendra virus: 125 years of equine infectious diseases. Vet. Record, 173: 186-189.

Srinivasan, A., C.N. Kraus, D. DeShazer, P.M. Becker and J.D. Dick et al., 2001. Glandersin a military research microbiologist. New Engl. J. Med., 345: 256-258.

Stryszak, A., 1986. Diagnostic value of the rose bengal plate test in the diagnosis of bovine brucellosis. Pol. Vet. Arch., 26: 23-38. 
Taylor, L.H., S.M. Latham and M.E.J. Woolhouse, 2001. Risk factors for human disease emergence. Philos. Trans. R. Soc. London B: Biol. Sci., 356: 983-989.

Van Zandt, K.E., M.T. Greer and H.C. Gelhaus, 2013. Glanders: An overview of infection in humans. Orphanet J. Rare Dis., Vol. 8. 10.1186/1750-1172-8131

Vazquez-Boland, J.A., M. Kuhn, P. Berche, T. Chakraborty and G. Dominguez- Bernal et al., 2001. Listeria pathogenesis and molecular virulence determinants. Clin. Microbiol. Rev., 14: 584-640.
Wang, L.F. and G. Crameri, 2014. Emerging zoonotic viral diseases. Rev. Sci. Tech. Off. Int. Epiz., 33: 569-581.

Wittig, M.B., P. Wohlsein, R.M. Hagen, S. Al Dahouk and H. Tomaso et al., 2006. Glanders-a comprehensive review. Dtsch Tierarztl Wochenschr, 113: 323-330.

Yakubu, Y., A.B. Shuaibu, A.M. Ibrahim, U.L. Hassan and R.J. Nwachukwu, 2018. Risk of Shiga toxigenic Escherichia coli $\mathrm{O} 157$ : $\mathrm{H} 7$ infection from raw and fermented milk in Sokoto Metropolis, Nigeria. J. Pathog., 2018: 1-5. 